\title{
Tricuspid annulus diameter does not predict the development of tricuspid regurgitation after mitral valve repair for mitral regurgitation due to degenerative diseases
}

\author{
Tirone E. David, MD, Carolyn M. David, BN, and Cedric Manlhiot, PhD
}

\section{ABSTRACT}

Background: Heart valve surgery guidelines suggest that tricuspid valve annuloplasty may be beneficial in patients with a tricuspid annulus (TA) $\geq 40 \mathrm{~mm}$ even in the absence of functional tricuspid regurgitation (TR) at the time of surgery for left-sided valve lesions (class $2 \mathrm{a}$ ). Given the broad spectrum of degenerative diseases that affect the atrioventricular valves, we hypothesize that this measurement might not be predictive of TR after mitral valve (MV) repair.

Methods: The diameter of the TA was measured preoperatively in a cohort of 312 consecutive patients who had isolated MV repair for degenerative diseases. The mean TA diameter was $36 \mathrm{~mm}$ (95\% confidence interval [CI], 35-37 mm). TA $\geq 40 \mathrm{~mm}$ was present in 80 patients. The median duration of echocardiographic follow-up was 6.7 years (interquartile range, 5.4-8.4 years), and was 100\% complete. The main study endpoint was postoperative TR of moderate or greater degree.

Results: Thirty patients had new or persistent TR at some point during follow-up. The probability of postoperative TR at 7 years was 6.6\% (95\% CI, 4.6\%-9.4\%) for all patients, 6.8\% (95\% CI, 4.6\%-10.4\%) for TA $<40 \mathrm{~mm}$, and $6.0 \%(95 \%$ CI, $2.9 \%-12.2 \%$ ) for TA $\geq 40 \mathrm{~mm}$. Preoperative TA diameter was not associated with the odds of postoperative TR in either the univariable or multivariable regression models. In these analyses, preoperative TR was the strongest predictor of postoperative TR.

Conclusions: TA $\geq 40 \mathrm{~mm}$ is not predictive of the development of postoperative TR after MV repair for degenerative diseases. (J Thorac Cardiovasc Surg 2018;155:2429-36)

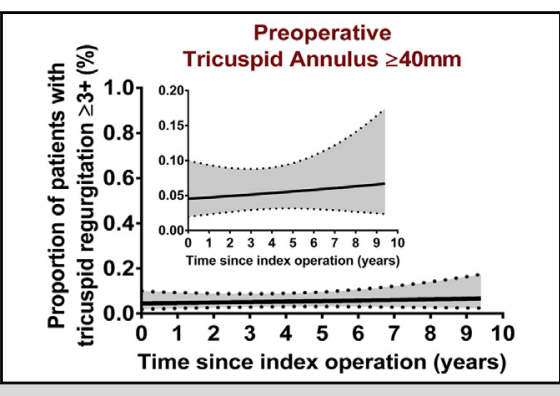

Probability of postoperative tricuspid regurgitation after mitral valve repair for degenerative disease in patients with a tricuspid annulus diameter $\geq 40 \mathrm{~mm}$

\section{Central Message}

A preoperative tricuspid annulus diameter $\geq 40 \mathrm{~mm}$ was not associated with the development of postoperative functional tricuspid regurgitation after mitral valve repair for degenerative diseases.

\section{Perspective}

Heart valve guidelines suggest that tricuspid valve annuloplasty should be performed during left side valve operations in the absence of tricuspid regurgitation if the tricuspid annulus diameter is $\geq 40 \mathrm{~mm}$. In this observational study, preoperative tricuspid annulus diameter was not associated with odds of postoperative tricuspid regurgitation in either univariable or multivariable regression models.

See Editorial Commentary page 2437

See Editorial page 2427.
From the Division of Cardiovascular Surgery, Peter Munk Cardiac Centre, Toronto General Hospital, University of Toronto, Toronto, Ontario, Canada.

This project was funded by Miranda and Anthony Wong.

Read at the 97th Annual Meeting of The American Association for Thoracic Surgery, Boston, Massachusetts, April 29-May 3, 2017.

Received for publication March 17, 2017; revisions received Nov 13, 2017; accepted for publication Dec 3, 2017; available ahead of print Feb 22, 2018.

Address for reprints: Tirone E. David, MD, 200 Elizabeth St, 4N453, Toronto M5G 2C4, Ontario, Canada (E-mail: tirone.david@uhn.ca).

$0022-5223 / \$ 36.00$

Copyright (c) 2018 by The American Association for Thoracic Surgery

https://doi.org/10.1016/j.jtcvs.2017.12.126
Functional tricuspid regurgitation (TR) results from leaflet tethering secondary to right ventricular and annular dilatation. ${ }^{1}$ Right ventricular dilatation is often caused

Scanning this QR code will take you to the article title page. To view the AATS Annual Meeting Webcast, see the URL next to the webcast thumbnail.

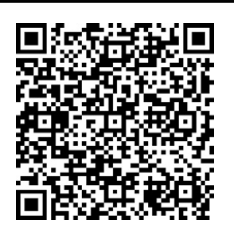




$$
\begin{aligned}
& \text { Abbreviations and Acronyms } \\
& \text { MA }=\text { mitral annulus } \\
& \text { MV }=\text { mitral valve } \\
& \text { MR }=\text { mitral regurgitation } \\
& \text { TA }=\text { tricuspid annulus } \\
& \text { TR }=\text { tricuspid regurgitation } \\
& \text { TV }=\text { tricuspid valve } \\
& \text { TVA }=\text { tricuspid valve annuloplasty }
\end{aligned}
$$

by increased right ventricular pressure and/or volume overload, but can also be caused by right ventricular infarction or idiopathic cardiomyopathy.

Functional TR is common in patients with advanced left-sided heart valve diseases. Current guidelines on the management of heart valve diseases ${ }^{2,3}$ suggest that tricuspid valve annuloplasty (TVA) may be beneficial in patients with trace or mild functional TR and a tricuspid annulus (TA) diameter $\geq 40 \mathrm{~mm}$ as measured by echocardiography or $70 \mathrm{~mm}$ as measured by direct inspection of the tricuspid valve (TV) during surgery for left-sided valve lesions (class 2a, meaning that it should be considered, but the evidence is conflicting).

The concept of performing TVA based on TA dilatation rather than on TR grade was introduced by Dreyfus and colleagues, ${ }^{4}$ who hypothesized that a dilated TA is a permanent and even progressive lesion that if left unattended at the time of mitral valve (MV) repair, may progress and cause severe TR postoperatively. There is evidence that the TA dilates and changes its shape from elliptical to spherical in patients with severe TR. ${ }^{1,5}$ Whether TVA should be performed when the TA diameter measures $\geq 40 \mathrm{~mm}$ remains controversial, however.

Degenerative diseases of the MV, the most common causes of mitral regurgitation (MR) in North America, include a broad spectrum of lesions in the leaflets and annuli of the atrioventricular valves. We hypothesize that a TA diameter $\geq 40 \mathrm{~mm}$ in patients with MR due to degenerative diseases is not predictive of postoperative TR after MV repair for degenerative diseases. In this study, we examined the effect of TA diameter in the development of TR after MV repair for MR due to degenerative diseases.

\section{PATIENTS AND METHODS}

This study was approved by the Review Ethics Board of University Health Network, and individual patient consent was required. All patients $(\mathrm{n}=1247)$ who underwent MV repair for MR due to degenerative disease between January 1985 and December 2010 performed by a single surgeon (Dr David) have been followed prospectively. Patients who underwent surgery after October 2005 had preoperative TA diameters measured during both systole and diastole. This new entry was prompted by the report by Dreyfus and colleagues supporting the importance of preoperative TA size in predicting postoperative TR after MV repair. ${ }^{4}$ Of the 335 patients who underwent surgery between October 2005 and December 2010, 25 had concomitant TVA and were excluded from this study.

The patients were followed by the referring cardiologists and seen by the surgeon at 2 to 3 months and then contacted by his research personnel every 2 to 3 years thereafter. Echocardiography was performed preoperatively, during surgery, at 1 week postsurgery, and at each follow-up contact unless there was a reason to image the heart more often. A total of 984 postoperative echocardiograms were available for analysis; 303 patients (97\%) had more than 1 study, and $87 \%$ had more than 2 studies. The majority of postoperative studies were performed at a certified echocardiography laboratory and read by an experienced echocardiographer. MR and TR were recorded as none $(0)$, trace $(1+)$, mild $(2+)$, moderate $(3+)$, or severe $(4+)$, according to the guidelines of the American Society of Echocardiography. ${ }^{6}$ If the echocardiographer reported the MR or TR as "mild to moderate" or "moderate to severe," which occurred in 27 studies, the recorded images were reviewed by blinded echocardiographers from our institution and entered into the database according to their interpretation as mild $(n=6)$, moderate $(\mathrm{n}=19)$, or severe $(\mathrm{n}=2)$.

The TA and mitral annulus (MA) diameters were measured preoperatively by transesophageal echocardiography at end of diastole in a 4-chamber view at $0^{\circ}$ for the TA and at $0^{\circ}$ and $90^{\circ}$ for the MA.

Adverse events were recorded according to guidelines set by cardiac surgical societies. ${ }^{7}$ The cause of death was determined by hospital chart review, death certificate, or information from the physician who was caring for the patient at that time. Clinical and echocardiographic follow-up was $100 \%$ complete; the median duration of clinical follow-up was 7.1 years (interquartile range [IQR], 5.8-8.8 years), and the median duration of echocardiographic follow-up was 6.7 years (IQR, 5.4-8.4 years). There were no substantial differences in the number of patients reaching landmark follow-up durations between clinical and imaging follow-up.

\section{Statistical Analysis}

Data are presented as median with IQR (ie, 25th and 75th percentiles) and frequencies as appropriate. Pearson correlation was used to determine the association between preoperative TA and MA size along with linear regression models. Nonlinearity of the association between preoperative TA and MA size was assessed through various mathematical transformations of MA size; the Akaike information criterion was used to compare the different models. Linear regression was used to determine the associations between preoperative TA and preoperative TR and degree of myxomatous degeneration (separately, both modeled as categorical variables). The Kaplan-Meier method was used to estimate survival over time. The cumulative incidences of stroke and reoperation were calculated with death as a competing risk. Given the low number of patients experiencing any of these 3 outcomes, no attempt was made to identify risk factors.

The progression of moderate or severe TR over time was modeled using logistic regression models adjusted for repeated measures through an autoregressive covariance structure (mixed longitudinal regression models). The autoregressive covariance structure was chosen specifically because this structure assumes homogenous variance over time and correlations between the different observations in the same patient that decline exponentially over time. Both assumptions are true in this type of data (repeated echocardiograms over time). Univariable risk factor analysis was performed using this approach.

Given the limited number of outcomes available for analysis, we elected to perform multivariable risk factor analysis using a priori selection of variables based on clinical relevance. Variables selected as potential risk factors were sex, age at the time of surgery, preoperative atrial fibrillation/ concomitant maze procedure, preoperative hypertension, preoperative TA $\geq 40 \mathrm{~mm}$, preoperative TR grade, and time since the index procedure.

The association between $\mathrm{TA} \geq 40 \mathrm{~mm}$ and progression of moderate or severe TR over time was assessed for various subgroups of patients to determine whether there was any interaction between clinical characteristics and the effect of preoperative TA size on postoperative TR. 
TABLE 1. Patient profile stratified by preoperative TA diameter

\begin{tabular}{|c|c|c|c|c|}
\hline Variable & Entire cohort $(n=312)$ & TA $<40$ mm $(\mathrm{n}=\mathbf{2 3 2})$ & $\mathbf{T A} \geq \mathbf{4 0} \mathbf{~ m m}(\mathrm{n}=\mathbf{8 0})$ & $P$ value \\
\hline Age, y, median (IQR) & $58(50-67)$ & $59(49-67)$ & $57(50-66)$ & .89 \\
\hline Male sex, $\mathrm{n}(\%)$ & $221(70.8)$ & $151(65.1)$ & $70(87.5)$ & $<.001$ \\
\hline Body surface area, $\mathrm{m}^{2}$ (IQR) & $1.91(1.75-2.08)$ & $1.90(1.72-2.06)$ & $2.00(1.85-2.11)$ & $<.001$ \\
\hline Body mass index, $\mathrm{kg} / \mathrm{m}^{2}$, median (IQR) & $25.9(23.6-28.4)$ & $25.8(23.2-28.4)$ & $26.3(24.2-28.6)$ & .42 \\
\hline \multicolumn{5}{|l|}{ Preoperative heart rhythm, n (\%) } \\
\hline Atrial fibrillation or flutter & $44(14.1)$ & $25(10.8)$ & $19(23.8)$ & .008 \\
\hline History of atrial fibrillation & $10(3.2)$ & $7(3.0)$ & $3(3.8)$ & .75 \\
\hline Complete heart block/pacemaker & $1(0.3)$ & $0(0.0)$ & $1(1.3)$ & .26 \\
\hline \multicolumn{5}{|l|}{ Previous heart operations, $\mathrm{n}(\%)$} \\
\hline Coronary artery bypass & $2(0.6)$ & $2(0.9)$ & $0(0.0)$ & 1.00 \\
\hline Percutaneous coronary interventions & $2(0.6)$ & $2(0.9)$ & $0(0.0)$ & 1.00 \\
\hline Atrial septal defect closure & $2(0.6)$ & $2(0.9)$ & $0(0.0)$ & 1.00 \\
\hline NYHA functional classification, $\mathrm{n}(\%)$ & & & & .24 \\
\hline Class I & $93(29.8)$ & $72(31.0)$ & $21(26.3)$ & \\
\hline Class II & $124(39.7)$ & $96(41.4)$ & $28(35.0)$ & \\
\hline Class III & $91(29.2)$ & $62(26.7)$ & $29(36.3)$ & \\
\hline Class IV & $4(1.3)$ & $2(0.9)$ & $2(2.5)$ & \\
\hline Left ventricular ejection fraction, $\mathrm{n}(\%)$ & & & & .08 \\
\hline$\geq 60$ & $258(82.7)$ & $198(85.3)$ & $60(75.0)$ & \\
\hline $40-59$ & $46(14.7)$ & $28(12.1)$ & $18(22.5)$ & \\
\hline $20-39$ & $8(2.6)$ & $6(2.6)$ & $2(2.5)$ & \\
\hline \multicolumn{5}{|l|}{ Symptomatology, n (\%) } \\
\hline Congestive heart failure & $108(34.6)$ & $76(32.8)$ & $32(40.0)$ & .028 \\
\hline Angina pectoris & $13(4.2)$ & $13(5.6)$ & $0(0.0)$ & .03 \\
\hline Syncopal episodes & $4(1.3)$ & $4(1.7)$ & $0(0.0)$ & .58 \\
\hline \multicolumn{5}{|l|}{ Associated conditions, $\mathrm{n}(\%)$} \\
\hline Hyperlipidemia & $111(35.6)$ & $88(37.9)$ & $23(28.8)$ & .18 \\
\hline Family history of CAD & $135(43.3)$ & $106(45.7)$ & $29(36.3)$ & .15 \\
\hline Diabetes mellitus & $15(4.8)$ & $12(5.2)$ & $3(3.8)$ & .77 \\
\hline Hypertension & $115(36.9)$ & 87 (37.5) & $28(35.0)$ & .79 \\
\hline Smoking history & $124(39.7)$ & $90(38.8)$ & $34(42.5)$ & .60 \\
\hline Severe COPD & $5(1.6)$ & $4(1.7)$ & $1(1.3)$ & 1.00 \\
\hline Previous stroke or TIA & $9(2.9)$ & $9(3.9)$ & $0(0.0)$ & .12 \\
\hline Infective endocarditis & $14(4.5)$ & $12(5.2)$ & $2(2.5)$ & .53 \\
\hline Coronary artery disease & $43(13.8)$ & $31(13.4)$ & $12(15.0)$ & .71 \\
\hline
\end{tabular}

$T A$, Tricuspid annulus; $I Q R$, interquartile range; $N Y H A$, New York Heart Association; $C A D$, coronary artery disease; $C O P D$, chronic obstructive pulmonary disease; $T I A$, transient ischemic attack.

Missing data were rare $(2.0 \%)$ and distributed randomly; consequently, mean imputation was used to handle the few missing data elements. There were no missing outcomes data. All statistical analyses were performed using SAS version 9.4 (SAS Institute, Cary, NC).

\section{RESULTS}

Patient profile and operative data for the entire cohort and stratified by preoperative TA size are shown in Tables 1 and 2 , respectively.

\section{Clinical Outcomes}

There were 2 operative and 11 late deaths, including 2 due to stroke, 1 due to endocarditis, and 10 due to noncardiac causes. There was $1 \mathrm{MV}$ re-repair for recurrent $\mathrm{MR}$ at 5 years after surgery and $1 \mathrm{MV}$ re-repair for mitral stenosis caused by pannus at 7 years after surgery. Six patients sustained a stroke, 2 of whom died. Table 3 presents data on the freedom from morbid events over time.

\section{Tricuspid and Mitral Valves}

There were modest positive linear associations between preoperative TA and MA diameters (Figure 1) and between TA diameter and TR grade (Figure 2), but no association between TA diameter and the degree of MV degeneration (Figure 3). Eighty patients $(26 \%)$ had a TA diameter $\geq 40 \mathrm{~mm}$ before surgery. Thirty patients had new or persistent $\mathrm{TR} \geq 3+$ at some point during follow-up. Figure 4 shows the probability of postoperative $\mathrm{TR} \geq 3+$ during follow-up in all patients, in patients with TA diameter $\geq 40 \mathrm{~mm}$, and in patients with TA diameter 
TABLE 2. Operative data stratified by preoperative TA diameter

\begin{tabular}{|c|c|c|c|c|}
\hline Variable & Entire cohort $(n=312)$ & TA $<40 \mathbf{m m}(\mathrm{n}=\mathbf{2 3 2})$ & $\mathrm{TA} \geq 40 \mathrm{~mm}(\mathrm{n}=\mathbf{8 0})$ & $P$ value \\
\hline MV prolapse, n (\%) & & & & .46 \\
\hline None (annular dilatation) & $12(3.9)$ & $11(4.7)$ & $1(1.3)$ & \\
\hline Anterior leaflet & $21(6.7)$ & $14(6.0)$ & $7(8.8)$ & \\
\hline Posterior leaflet & $112(35.9)$ & $84(36.2)$ & $28(35.0)$ & \\
\hline Both leaflets & $167(53.5)$ & $123(53.0)$ & $44(55.0)$ & \\
\hline \multicolumn{5}{|l|}{ Echocardiographic measurements, mm, median (IQR) } \\
\hline $\mathrm{MA}$ at $0^{\circ}$ & $40(37-45)$ & $40(36-43)$ & $43(39-47)$ & $<.001$ \\
\hline MA at $90^{\circ}$ & $40(37-45)$ & $40(36-44)$ & $42(39-47)$ & .02 \\
\hline $\mathrm{TA}$ at $0^{\circ}$ & $35(32-40)$ & $34(32-36)$ & $41(40-42)$ & $<.001$ \\
\hline TR grade, $n(\%)$ & & & & .06 \\
\hline None or trace $(0-1+)$ & $150(48.1)$ & $120(51.8)$ & $30(37.5)$ & \\
\hline Mild (2+) & $144(46.2)$ & $101(43.5)$ & $43(53.8)$ & \\
\hline Moderate $(3+)$ & $18(5.8)$ & $11(4.7)$ & $7(8.8)$ & \\
\hline Degree of MV myxomatous degeneration, $\mathrm{n}(\%)^{*}$ & & & & .94 \\
\hline Mild & $105(33.7)$ & $79(34.1)$ & $26(32.5)$ & \\
\hline Moderate & $135(43.3)$ & $99(42.7)$ & $36(45.0)$ & \\
\hline Advanced & $72(23.1)$ & $54(23.3)$ & $19(22.5)$ & \\
\hline Dystrophic calcification of the annulus, $\mathrm{n}(\%)$ & $12(3.9)$ & $10(4.3)$ & $2(2.5)$ & .74 \\
\hline \multicolumn{5}{|l|}{ Operation performed, $\mathrm{n}(\%)$} \\
\hline MV repair with Simplici-T band & $312(100)$ & $232(100)$ & $80(100)$ & 1.00 \\
\hline Chordal replacement & $252(80.8)$ & $184(79.3)$ & $68(85.0)$ & .32 \\
\hline Reconstruction of the MA & $12(3.9)$ & $10(4.3)$ & $2(2.5)$ & .74 \\
\hline Maze for atrial fibrillation & $54(17.3)$ & $32(13.8)$ & $22(27.5)$ & .01 \\
\hline Repair of atrial septal defect & $15(4.8)$ & $9(3.9)$ & $6(7.5)$ & .23 \\
\hline Replacement of the ascending aorta & $7(2.2)$ & $6(2.6)$ & $1(1.3)$ & .68 \\
\hline Coronary artery bypass & $43(13.8)$ & $31(13.4)$ & $12(15.0)$ & .71 \\
\hline Resection of atrial myxoma & $1(0.3)$ & $1(0.4)$ & $0(0.0)$ & 1.00 \\
\hline Septal myectomy & $2(0.6)$ & $1(0.4)$ & $1(1.3)$ & .45 \\
\hline Aortic clamping time, min, median (IQR) & $66(47-81)$ & $63(46-100)$ & $72(53-84)$ & .06 \\
\hline Cardiopulmonary bypass time, min, median (IQR) & $82(64-101)$ & $81(62-100)$ & $92(71-106)$ & .04 \\
\hline
\end{tabular}

$T A$, Tricuspid annulus; $M V$, mitral valve; $I Q R$, interquartile range; $M A$, mitral annulus; $T R$, tricuspid regurgitation. *Degree of myxomatous degeneration.

$<40 \mathrm{~mm}$ separately. Table 4 present the results of univariable analyses of variables associated with postoperative $\mathrm{TR} \geq 3+$, and Table 5 presents the results of multivariable analysis. Preoperative TA diameter was not associated with the odds of postoperative TR in either the univariable or multivariable regression models. This remained true regardless of whether TA size was modeled as a continuous variable, as an ordinal variable, or using the threshold of $\geq 40 \mathrm{~mm}$. There was a significant association between TA diameter indexed to body surface area and odds of postoperative TR in univariable analysis (Table 4); however, this association did not remain significant in the multivariable regression model (Table 5). In subgroup analysis, preoperative TA diameter $\geq 40 \mathrm{~mm}$ was not associated with increased risk of postoperative TR in any subgroup of patients except patients with a preoperative left ventricular ejection fraction $<60 \%$ (Table 6).

Twelve patients developed $\mathrm{MR} \geq 3$, and 1 patient developed mitral stenosis due to pannus during follow-up.

TABLE 3. Clinical outcomes: freedom from mortality from Kaplan-Meier estimates, cumulative incidences of reoperation and stroke over time with death as a competing risk, and number of patients with data available at different follow-up landmarks

\begin{tabular}{lcccc}
\hline \multicolumn{1}{c}{ Outcome } & $\mathbf{1 ~ y}$ & $\mathbf{3 ~ y}$ & $\mathbf{5 ~ y}$ & $\mathbf{1 0} \mathbf{y}$ \\
\hline Survival, \% $(95 \%$ CI) & $99.4(97.5-99.8)$ & $98.4(96.1-99.3)$ & $97.7(95.2-98.9)$ & $90.8(74.2-96.9)$ \\
Reoperation, CuI (95\% CI) & 0.0 & $0.7(0.2-2.6)$ & $0.7(0.2-2.6)$ & $0.7(0.2-2.6)$ \\
Stroke, CuI (95\% CI) & $0.3(0.1-2.3)$ & $0.5(0.2-2.5)$ & $1.3(0.5-3.5)$ & $2.9(1.1-7.3)$ \\
No. of patients, clinical & 310 & 297 & 277 & 16 \\
No. of patients, imaging & 301 & 289 & 255 & 10 \\
\hline
\end{tabular}

CI, Confidence interval; $\mathrm{CuI}$, cumulative incidence. 


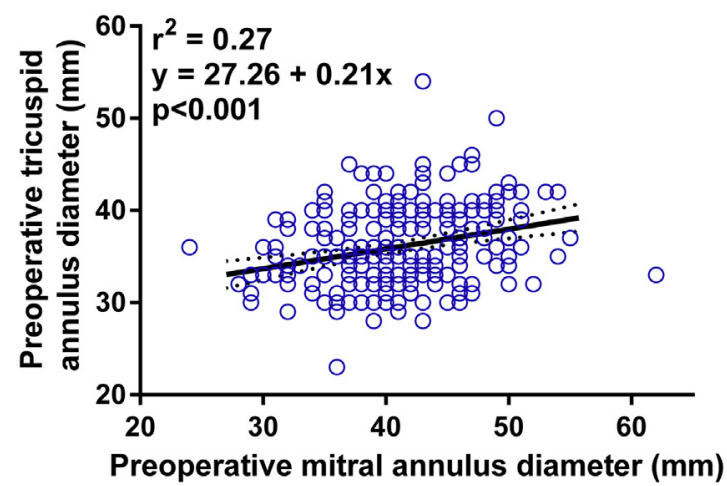

FIGURE 1. Correlation of preoperative tricuspid annulus size and preoperative mitral annulus size.

\section{DISCUSSION}

The concept of performing TVA based on the diameter of the TA rather than on the severity of TR was introduced by Dreyfus and colleagues ${ }^{4}$ in 2005 . These investigators systematically explored the TV at the time of MV repair for MR due to various pathologies in 311 patients, and performed TVA whenever the distance from the anteroseptal commissure to the anteroposterior commissure was $\geq 70 \mathrm{~mm} .{ }^{4}$ They found that this approach greatly reduced the risk of developing TR after MV repair. ${ }^{4}$ We are not aware of any study that has correlated this surgical measurement in the arrested heart with preoperative TA diameter, but $40 \mathrm{~mm}$ appears in the guidelines. ${ }^{2,3}$

Although we do not dispute that a dilated TA is often associated with functional TR, the value of $40 \mathrm{~mm}$ as a cutoff to recommend TVA without TR at the time of MV repair for degenerative MR needs further evaluation. The TV leaflets, like the MV leaflets, vary in size in patients with degenerative diseases. Patients with fibroelastic deficiency frequently have small MV leaflets, so small that at one time we were reluctant to use an annuloplasty ring or band for fear of creating mitral stenosis. ${ }^{8}$ The TV leaflets are also small in these patients, and a TA of $40 \mathrm{~mm}$ is likely too large, and this TVA is probably

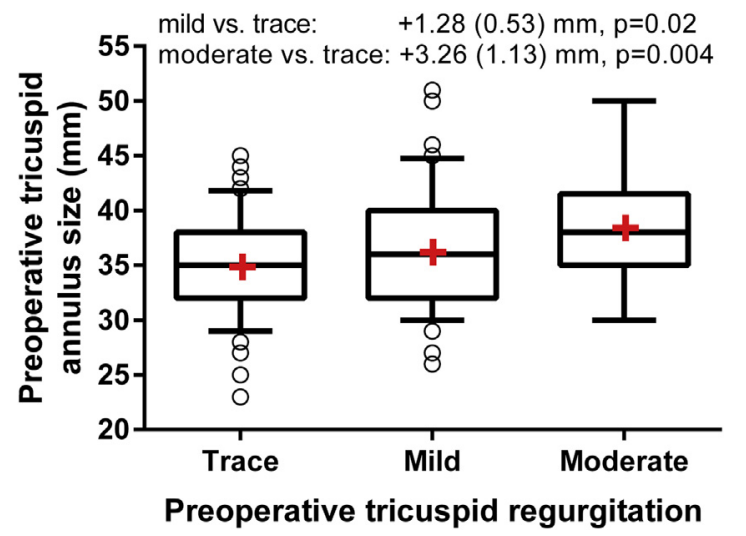

FIGURE 2. Tricuspid annulus size versus preoperative tricuspid regurgitation grade.

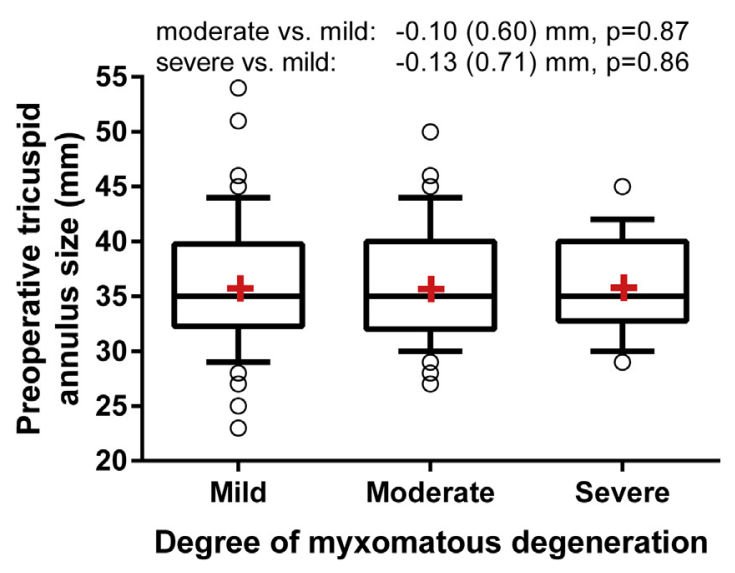

FIGURE 3. Tricuspid annulus size versus degree of degeneration of the mitral valve.

necessary to prevent late TR. On the other hand, patients with myxomatous degeneration of the MV frequently have large leaflets with large MAs and also large TV leaflets with larger TAs. This type of degenerative disease is present in most of our patients, and a TA of $40 \mathrm{~mm}$ is likely normal and is only rarely associated with severe TR (at least in our experience), and when this association is present, it is often a result of leaflet prolapse rather than annular dilatation. In this study, TA diameter was moderately correlated with MA diameter (Figure 1), as well as with the severity of preoperative TR (Figure 2), but was not correlated with the degree of myxomatous degeneration. This finding was surprising, because we expected to find large TV leaflets and consequently larger TAs in patients with more advanced degrees of myxomatous degeneration.

TA $\geq 40 \mathrm{~mm}$ or $\mathrm{TA} \geq 21 \mathrm{~mm} / \mathrm{m}^{2}$ did not predict the development of postoperative TR. Preoperative TA diameter was not associated with postoperative TR in either the univariable or multivariable regression models. This remained true regardless of whether TA diameter was modeled as a continuous variable, as an ordinal variable, or using the threshold of $\geq 40 \mathrm{~mm}$. There was a significant association between TA size indexed to body surface area and the odds of postoperative TR in univariable analysis; however, this association did not remain significant in the multivariable regression model. Preoperative TA diameter $\geq 40 \mathrm{~mm}$ was not associated with an increased risk of postoperative TR in any subgroup of patients except patients with a preoperative left ventricular ejection fraction $<60 \%$. In a recent study, we examined a much larger sample of patients and found that impaired left ventricular function was associated with the development of postoperative TR. ${ }^{9}$ The most powerful predictor of postoperative TR was the presence of untreated moderate TR before surgery.

We are not the first group to challenge the concept that TA $\geq 40 \mathrm{~mm}$ is predictive of postoperative functional TR after MV repair for degenerative diseases. Sordelli and colleagues, ${ }^{10}$ from Milan, Italy, prospectively evaluated 

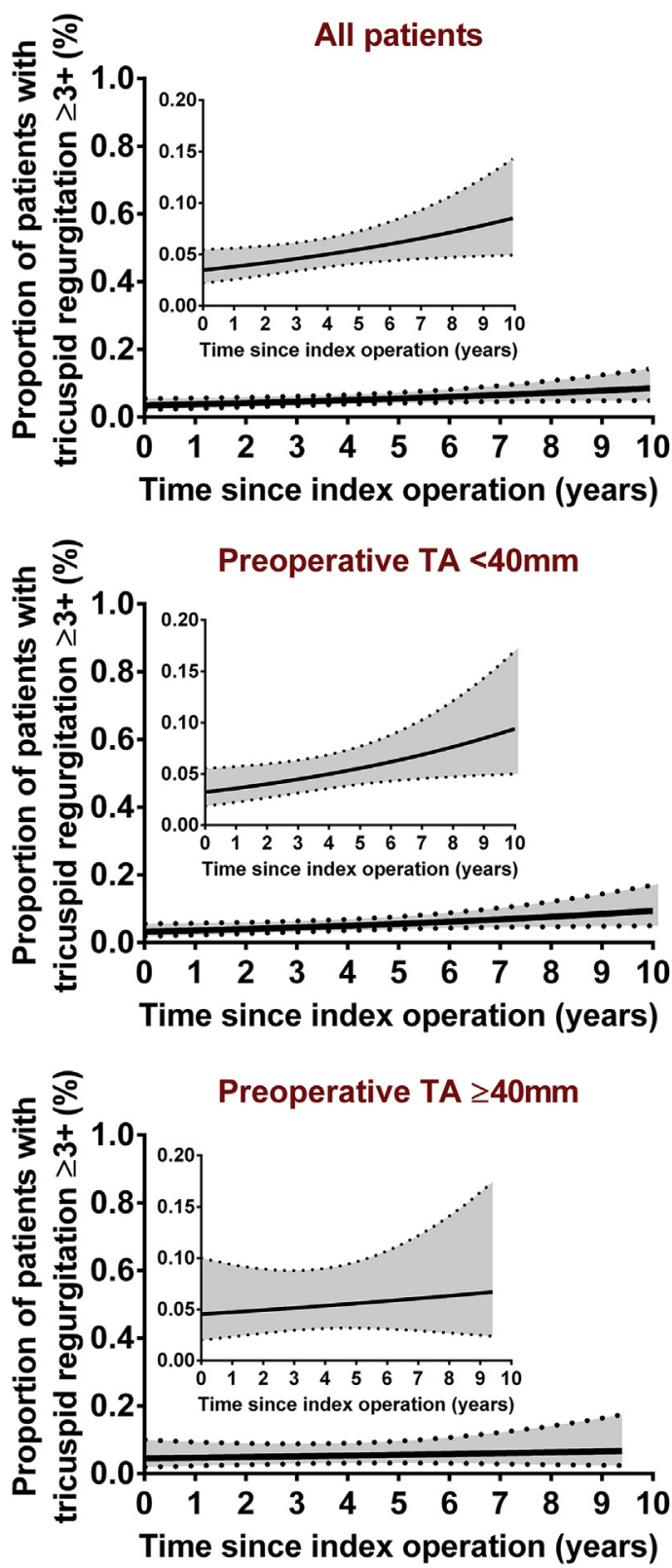

\begin{tabular}{|c|c|c|c|}
\hline & All patients & $\mathrm{TA}<40 \mathrm{~mm}$ & $\mathrm{TA}=40 \mathrm{~mm}$ \\
\hline 1 year & $3.8(2.6-5.6)$ & $3.6(2.2-5.7)$ & $4.7(2.3-9.3)$ \\
\hline 3 years & $4.7(3.4-6.1)$ & $4.5(3.1-6.3)$ & $5.1(3.0-8.8)$ \\
\hline 5 years & $5.4(4.1-7.2)$ & $5.5(3.9-7.6)$ & $5.6(3.2-9.7)$ \\
\hline 7 years & $6.6(4.6-9.4)$ & $6.8(4.6-10.4)$ & $6.0(2.9-12.2)$ \\
\hline
\end{tabular}

FIGURE 4. Estimated punctual probability of postoperative tricuspid regurgitation of moderate degree or greater over time (figure) and at specific follow-up landmarks (embedded table). Data are provided for in all patients (upper panel) and in patients with $\mathrm{TA}<40 \mathrm{~mm}$ and $\mathrm{TA} \geq 40 \mathrm{~mm}$.

the predictive value of TA diameter assessed by 3D transesophageal echocardiography in the development of TR in 706 patients who had undergone isolated MV repair for MR due to degenerative diseases $(77 \%$ with

TABLE 4. Univariable risk factor analysis for postoperative TR $\geq 3+$ over time

\begin{tabular}{|c|c|c|c|}
\hline Variable & OR & $95 \%$ CI & $P$ value \\
\hline Age (5-y increment) & 1.61 & $1.34-1.93$ & $<.001$ \\
\hline Time since operation (y) & 1.05 & $0.96-1.14$ & .27 \\
\hline Preoperative MA size (mm) & 0.99 & $0.92-1.06$ & .72 \\
\hline Preoperative $\mathrm{MV}$ area in $0^{\circ}$ & 0.99 & $0.93-1.06$ & .85 \\
\hline Preoperative $\mathrm{MV}$ area in $90^{\circ}$ & 0.96 & $0.89-1.03$ & .22 \\
\hline Female sex & 4.08 & $1.84-9.05$ & $<.001$ \\
\hline Atrial fibrillation/maze procedure & 4.63 & $2.10-10.24$ & $<.001$ \\
\hline Hypertension & 2.90 & $1.29-6.55$ & .01 \\
\hline $\begin{array}{l}\text { Preoperative TA size }(\mathrm{mm}) \\
\quad<35\end{array}$ & $\begin{array}{c}1.06 \\
\text { Reference }\end{array}$ & $0.99-1.15$ & .10 \\
\hline $35-39$ & 2.33 & $0.88-6.17$ & .09 \\
\hline $40-42$ & 1.74 & $0.57-5.31$ & .33 \\
\hline $42-45$ & 1.68 & $0.20-14.02$ & .63 \\
\hline$>45$ & 3.71 & $0.44-31.18$ & .23 \\
\hline Preoperative TA size $\geq 40 \mathrm{~mm}$ & 1.13 & $0.48-2.68$ & .77 \\
\hline TA size $/ \mathrm{BSA}>21 \mathrm{~mm} / \mathrm{m}^{2}$ & 2.416 & $1.279-4.565$ & .007 \\
\hline Preoperative TR $\geq 3+$ & 13.6 & $5.71-32.59$ & $<.001$ \\
\hline \multicolumn{4}{|c|}{ Preoperative degeneration of MV (reference: mild) } \\
\hline Moderate & 0.86 & $0.36-2.06$ & .74 \\
\hline Severe & 0.39 & $0.14-1.07$ & .07 \\
\hline Preoperative LV grade (per grade) & 1.03 & $0.49-2.17$ & .94 \\
\hline
\end{tabular}

$O R$, Odds ratio; $C I$, confidence interval; $M A$, mitral annulus; $M V$, mitral valve; $T A$, tricuspid annulus; $B S A$, body surface area; $T R$, tricuspid regurgitation; $L V$, left ventricular.

myxomatous diseases, with a broad spectrum of lesions, and $23 \%$ with fibroelastic deficiency). They performed a detailed analysis of the diastolic and systolic TA diameters (anteroposterior and septolateral) and the outcomes of

TABLE 5. Multivariable risk factor analysis for postoperative TR $\geq 3+$ over time for preoperative TA size $\geq \mathbf{4 0} \mathrm{mm}$ and preoperative TA size indexed to body surface area

\begin{tabular}{lll}
\hline \multicolumn{1}{c}{ Variable } & \multicolumn{1}{c}{ OR $(\mathbf{9 5} \%$ CI) } & $\boldsymbol{P}$ value \\
\hline Preoperative TA size $\geq 40 \mathrm{~mm}$ & & \\
Time since operation (per year) & $1.094(0.986-1.213)$ & .09 \\
Age (5-y increment) & $1.312(1.054-1.633)$ & .02 \\
Female sex & $4.244(1.748-10.307)$ & .001 \\
Atrial fibrillation/maze procedure & $1.744(0.666-4.567)$ & .26 \\
Hypertension & $2.485(0.958-6.449)$ & .06 \\
Preoperative TR $\geq 3+$ & $7.629(2.105-27.658)$ & .002 \\
Preoperative TA size $\geq 40 \mathrm{~mm}$ & $1.405(0.492-4.014)$ & .53 \\
Preoperative TA indexed to BSA & & \\
Time since operation (per year) & $1.094(0.986-1.213)$ & .09 \\
Age (5-y increment) & $1.294(1.050-1.594)$ & .02 \\
Female sex & $3.735(1.445-9.652)$ & .007 \\
Atrial fibrillation/maze procedure & $1.849(0.680-5.024)$ & .23 \\
Hypertension & $2.513(0.965-6.546)$ & .06 \\
Preoperative TR $\geq 3+$ & $7.537(2.141-26.528)$ & .002 \\
Preoperative TA indexed to BSA & $1.024(0.905-1.160)$ & .70 \\
\hline OR, Odds ratio; $C I$, confidence interval; $T A$, tricuspid annulus; $T R$, tricuspid \\
regurgitation; BSA, body surface area. &
\end{tabular}


TABLE 6. Association between preoperative TA size $\geq \mathbf{4 0} \mathrm{mm}$ and postoperative $T R \geq 3+$ over time for various subgroups of patients

\begin{tabular}{|c|c|c|}
\hline Patient subgroup & OR $(95 \%$ CI $)$ & $P$ value \\
\hline \multicolumn{3}{|l|}{ Age (y) } \\
\hline$<50$ & $3.376(0.214-53.372)$ & .39 \\
\hline $50-59$ & $0.908(0.750-10.930)$ & .94 \\
\hline $60-69$ & $0.626(0.130-3.011)$ & .56 \\
\hline$\geq 70$ & $2.013(0.605-6.701)$ & .25 \\
\hline \multicolumn{3}{|l|}{ Sex } \\
\hline Male & $1.191(0.366-3.876)$ & .77 \\
\hline Female & $3.210(0.883-11.666)$ & .08 \\
\hline \multicolumn{3}{|c|}{ Atrial fibrillation/maze procedure* } \\
\hline Yes & $1.472(0.474-4.573)$ & .50 \\
\hline No & $0.474(0.102-2.207)$ & .34 \\
\hline \multicolumn{3}{|l|}{$\operatorname{BSA}\left(\mathrm{m}^{2}\right)$} \\
\hline$\leq 1.75$ & $1.993(0.399-9.599)$ & .40 \\
\hline $1.76-1.90$ & $1.052(0.238-4.663)$ & .95 \\
\hline $1.91-2.05$ & $1.246(0.114-13.591)$ & .86 \\
\hline$>2.05$ & $2.158(0.403-11.547)$ & .37 \\
\hline \multicolumn{3}{|c|}{ Preoperative grade of TR } \\
\hline $1-2$ & $1.855(0.310-11.115)$ & .50 \\
\hline 2 & $1.518(0.449-5.135)$ & .50 \\
\hline$\geq 3+$ & $0.229(0.045-1.167)$ & .08 \\
\hline \multicolumn{3}{|c|}{ Preoperative degeneration of MV } \\
\hline Mild & $1.540(0.406-5.847)$ & .53 \\
\hline Moderate & $0.777(0.200-3.017)$ & .72 \\
\hline Severe & $1.642(0.310-8.695)$ & .56 \\
\hline \multicolumn{3}{|c|}{ Ejection fraction $(\%)$} \\
\hline$\geq 60$ & $0.672(0.242-1.860)$ & .44 \\
\hline$<60$ & $7.112(1.205-41.980)$ & .03 \\
\hline \multicolumn{3}{|c|}{ Preoperative MA size (mm) } \\
\hline$\leq 37$ & $1.713(0.410-7.151)$ & .46 \\
\hline $38-40$ & $2.536(0.257-25.013)$ & .43 \\
\hline $41-45$ & $0.264(0.029-2.390)$ & .24 \\
\hline$\geq 46$ & $1.626(0.262-10.091)$ & .60 \\
\hline
\end{tabular}

$O R$, Odds ratio; $C I$, confidence interval; $B S A$, body surface area; $T R$, tricuspid regurgitation; $M V$, mitral valve; $M A$, mitral annulus. *Given the small number of patients, the 41 patients with atrial fibrillation and the maze procedure, 13 patients with a history of atrial fibrillation and the maze procedure, and 3 patients with atrial fibrillation but no maze procedure were combined in a single category.

surgery after a mean follow-up of 2 years (range, $0.5-5$ years). TR decreased by 1 grade in $32 \%$ of the patients, remained unchanged in $62 \%$, and increased by 1 grade in $5.5 \%$, but only 3 patients developed moderate or severe TR. The authors concluded that "newly developed significant TR is a rare event after successful repair of degenerative MR," and that "analysis of TA does not predict early to midterm subsequent TR progression." 10 The MV pathology (myxomatous vs fibroelastic deficiency) was not entered into the multivariable models in that study. Of note, the TA and MA in our study are very similar to those reported by Sordelli and colleagues. ${ }^{10}$

A recent report based on the Society of Thoracic Surgeons database on TVA at the time of MV surgery indicated that concomitant TVA was performed in $14.3 \%$ of all MV operations, but in centers that performed more than $10 \mathrm{MV}$ operations per year, this percentage ranged from $75 \%$ in 2 centers to $<10 \%$ in more than 300 centers. ${ }^{11}$ In addition, TVA was performed in only $3.5 \%$ when the grade of TR was mild or less, $30.6 \%$ when it was moderate, and $75.6 \%$ when it was severe. ${ }^{11}$ However, as documented in this study and a previous study, ${ }^{9}$ preoperative moderate TR is associated with postoperative TR of moderate or severe degree after MV repair for degenerative diseases, and we now believe that TVA is appropriate in these patients. In addition, TVA should be considered in patients with longstanding atrial fibrillation, dilated right atrium, impaired left ventricular systolic function, and female, even in the absence of moderate or severe TR. ${ }^{9,12}$

\section{Study Limitations}

In this retrospective study, the TA and MA diameters were obtained intraoperatively, and the values may have been affected by the anesthetic, assisted ventilation, and loading conditions, which were not controlled for at the time of measurement. The sizes and areas of the TV leaflets were not measured to correlate with the diameter of TA and development of TR. In addition, TR after MV repair for degenerative diseases is uncommon, and the sample size of this study was too small and the duration of follow-up too short to enable a more detailed analysis of the variables associated with postoperative TR. Finally, given the limited sample size and the close to significant association between preoperative TA diameter as a continuous variable and increased odds of postoperative TR over time, we cannot exclude the possibility that the lack of association is in fact a type II error resulting from an underpowered comparison.

\section{CONCLUSIONS}

$\mathrm{TA} \geq 40 \mathrm{~mm}$ was not associated with the development of TR after MV repair for degenerative diseases, likely because of the variable size of the TV leaflets in patients with degenerative diseases. Preoperative moderate TR was the most powerful predictor of postoperative TR in multivariable analysis.

\section{Webcast}

You can watch a Webcast of this AATS meeting presentation by going to: https://aats.blob.core.windows. net/media/17AM/2017-05-01/BallroomABC/05-01-17_ BallroomABC_1450_David.mp4.

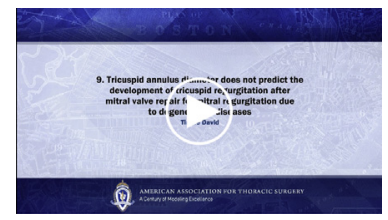




\section{Conflict of Interest Statement}

Authors have nothing to disclose with regard to commercial support.

\section{References}

1. Sagie A, Schwammenthal E, Padial LR, Vazquez de Prada JA, Weyman AE, Levine RA. Determinants of functional tricuspid regurgitation in incomplete tricuspid valve closure: Doppler color flow study of 109 patients. J Am Coll Cardiol. 1994;24:446-53.

2. Vahanian A, Alfieri O, Andreotti F, Antunes MJ, Barón-Esquivias G, Baumgartner $\mathrm{H}$, et al. Guidelines on the management of valvular heart disease (version 2012): the joint task force on the management of valvular heart disease of the European Society of Cardiology (ESC) and the European Association for Cardio-Thoracic Surgery (EACTS). Eur J Cardiothorac Surg. 2012;42:S1-44.

3. Nishimura RA, Otto CM, Bonow RO, Carabello BA, Erwin JP III, Guyton RA, et al. 2014 AHA/ACC guideline for the management of patients with valvular heart disease: executive summary: a report of the American College of Cardiology/American Heart Association task force on practice guidelines. J Am Coll Cardiol. 2014;63:2438-88.

4. Dreyfus GD, Corbi PJ, Chan KM, Bahrami T. Secondary tricuspid regurgitation or dilatation: which should be the criteria for surgical repair? Ann Thorac Surg. 2005;79:127-32.

5. Nemoto N, Lesser JR, Pedersen WR, Sorajja P, Spinner E, Garberich RF, et al. Pathogenic structural heart changes in early tricuspid regurgitation. $J$ Thorac Cardiovasc Surg. 2015;150:323-30.
6. Zoghbi WA, Enriquez-Sarano M, Foster E, Grayburn PA, Kraft CD, Levine RA, et al. American Society of Echocardiography. Recommendations for evaluation of the severity of native valvular regurgitation with two-dimensional and Doppler echocardiography. J Am Soc Echocardiogr. 2003;16:777-802.

7. Akins CW, Miller DC, Turina MI, Kouchoukos NT, Blackstone EH, Grunkemeier GL, et al. Guidelines for reporting mortality and morbidity after cardiac valve interventions. J Thorac Cardiovasc Surg. 2008;135:732-8.

8. David TE, Armstrong S, McCrindle BW, Manlhiot C. Late outcomes of mitral valve repair for mitral regurgitation due to degenerative disease. Circulation. 2013; 127:1485-92.

9. David TE, David CM, Fan CS, Manlhiot C. Tricuspid regurgitation is uncommon after mitral valve repair for degenerative diseases. J Thorac Cardiovasc Surg. 2017; 154:110-22.e1.

10. Sordelli C, Lancellotti P, Carlomagno G, Di Giannuario G, Alati E, De Bonis M, et al. Tricuspid annular size and regurgitation progression after surgical repair for degenerative mitral regurgitation. Am J Cardiol. 2016;118:424-31.

11. Badhwar V, Rankin JS, He M, Jacobs JP, Furnary AP, Fazzalari FL, et al. Performing concomitant tricuspid valve repair at the time of mitral valve operations is not associated with increased operative mortality. Ann Thorac Surg. 2017;103:587-93.

12. Ro SK, Kim JB, Jung SH, Choo SJ, Chung CH, Lee JW. Mild-to-moderate functional tricuspid regurgitation in patients undergoing mitral valve surgery. J Thorac Cardiovasc Surg. 2013;146:1092-7.

Key Words: tricuspid annulus, tricuspid insufficiency, tricuspid valve 